•研究报告・

\title{
上海苏州河治理中鱼类多样性及群落结构变化
}

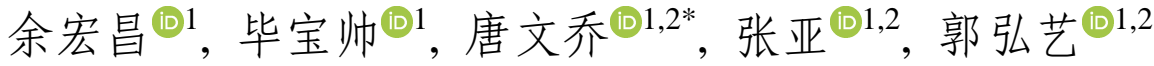

1. 上海海洋大学海洋动物系统分类与进化上海高校重点实验室, 上海 201306; 2. 上海海洋大学水产种质资源发掘与利用省部共建教育部 重点实验室, 上海 201306

摘要: 为了评估近20年来上海苏州河环境综合整治过程中鱼类多样性的变化状况，本文于2019年6月(夏季)和9月(秋季)对苏 州河13个断面的鱼类样本进行了采集, 对鱼类多样性和群落结构作了分析。结果显示, 2 次采集共获得鱼类样本 10,102 号, 隶 属于 8 目 15 科 37 属 45 种。夏季和秋季, 上游 8 个断面的鱼类均为 36 种, 下游 5 个断面则为 12 种和 15 种。从上游到下游, Shannon-Wiener多样性指数 $\left(H^{\prime}\right)$ 、Margalef种类丰富度指数 $(D)$ 和Simpson优势度指数 $(C)$ 总体呈逐渐降低的趋势。相对重要性 指数(IRI)显示, 夏秋两季上游断面共同的优势种为似鳊(Pseudobrama simoni), 下游为鲫(Carassius auratus)和泥鲉(Misgurnus anguillicaudatus)。丰度生物量曲线表明, 全河段鱼类群落结构总体上并不稳定, 特别是夏季的下游河段。Cluster聚类和非参 数多维标度排序分析可明显将鱼类群落分为上游群组(I)与下游群组(II), 似鳊、泥鱾、鲫、光泽黄滪鱼(Pelteobagrus nitidus) 和兴凯鱊(Acheilognathus chankaensis)等是造成群组间差异性的主要分歧种。与2001年的43种、2006年的28种相比，本次调查 的物种数出现了明显回升, 特别是下游河段。这种上游鱼类向下游迁移的趋势, 预示着下游中心城区与上游郊区河段的水质 差别正在缩小, 水生态系统恢复迹象明显。本文认为, 上下游之间鱼类群落结构差异的缩小以及趐嘴鲌(Culter alburnus)、红 鳍原鲌(Cultrichthys erythropterus)、棒花鱼(Abbottina rivularis)、子陵吻虾虎鱼(Rhinogobius giurinus)等在下游河段的出现，可 作为苏州河综合整治效果的重要生态标志。

关键词: 苏州河; 鱼类物种多样性; 群落结构; 指示鱼类

余宏昌, 毕宝帅, 唐文乔, 张亚, 郭弘艺 (2021) 上海苏州河治理中鱼类多样性及群落结构变化. 生物多样性, 29, 32-42. doi: 10.17520/biods.2020067. Yu HC, Bi BS, Tang WQ, Zhang Y, Guo HY (2021) Changes in fish diversity and assemblage during comprehensive restoration of the Suzhou River in Shanghai. Biodiversity Science, 29, 32-42. doi: 10.17520/biods.2020067.

\section{Changes in fish diversity and assemblage during comprehensive restoration of the Suzhou River in Shanghai}

Hongchang Yu ${ }^{(\mathbb{D} 1}$, Baoshuai Bi ${ }^{(\mathbb{D} 1}$, Wenqiao Tang ${ }^{\left(\mathbb{D} 1,2^{*}\right.}$, Ya Zhang ${ }^{(\mathbb{D} 1,2}$, Hongyi Guo ${ }^{(\mathbb{D} 1,2}$

1 Shanghai Universities Key Laboratory of Marine Animal Taxonomy and Evolution, Shanghai Ocean University, Shanghai 201306

2 Key Laboratory of Exploration and Utilization of Aquatic Genetic Resources, Ministry of Education, Shanghai Ocean University, Shanghai 201306

\section{ABSTRACT}

Aim: The Suzhou River, once a typical urban polluted river, flows through the central area of Shanghai. At the end of 1990s, the local government began to carry out the comprehensive treatment of the river environment. The water quality and ecosystem of the river have gradually improved. The purpose of this paper is to evaluate the changes in fish diversity and assemblage during the comprehensive restoration of the Suzhou River in Shanghai in the past two decades.

Methods: The paper sampled 13 sections along the Suzhou River in June (summer) and September (autumn) in 2019. Some statistical methods, such as diversity index, relative importance index (IRI), abundance-biomass comparison curve (ABC curve) and cluster analysis, are used to analyze the characteristic parameters of fish diversity and assemblage.

Results: A total of 10,102 fish samples were collected, comprising 45 species belonging to 8 orders, 15 families, and 37 genera. In summer and autumn, there were 36 species of fish in the upper reaches, 12 and 15 species, respectively, in

收稿日期: 2020-03-02; 接受日期: 2020-05-23

基金项目: 上海市生态环境局 2019 年苏州河鱼类群落专项调查项目和国家重点研发计划(2018YFD0900802)

* 通讯作者 Author for correspondence. E-mail: wqtang@shou.edu.cn 
the lower reaches. From upstream to downstream, the Shannon-Wiener diversity index $\left(H^{\prime}\right)$, the Margalef richness index $(D)$, and the Simpson dominance index $(C)$ showed gradual decreases. Relative importance index (IRI) showed that the common dominant species of the upper reaches in summer and autumn was Pseudobrama simoni, and the lower reaches were Carassius auratus and Misgurnus anguillicaudatus, respectively. The abundance-biomass comparison curve (ABC curve) revealed that the fish assemblage of the whole river was unstable, especially downstream in summer. Cluster analysis and non-metric multidimensional ordination, based on species and quantity, indicated that fish assemblage structure could be divided into two groups, e.g. upstream group I and downstream group II. Pseudobrama simoni, Misgurnus anguillicaudatus, Carassius auratus, Pelteobagrus nitidus and Acheilognathus chankaensis were the main discriminating species causing the differences between the two groups.

Conclusions: Compared with the 43 species in 2001 and 28 species in 2006, the species of fishes showed an increase, especially downstream. This trend of fish migration from upstream to downstream may indicate that water quality differences between the upper reaches and lower reaches is narrowing. The reduction of differences in the fish assemblage between upstream and downstream and the appearances of Culter alburnus, Cultrichthys erythropterus, Abbottina rivularis, and Rhinogobius giurinus in the lower reaches are ecological signs of the comprehensive restoration effects in the Suzhou River.

Key words: Suzhou River; species diversity of fish; assemblage; indicative fish

苏州河也称吴淞江，是长江最后一条大型支流 黄浦江的支流。发源于江苏太湖, 自青浦区进入上 海, 流经上海中心城区, 在外白渡桥汇入黄浦江; 在上海市境内长约 $53 \mathrm{~km}$, 河面宽一般为 $50-70 \mathrm{~m}$ 。 苏州河涉及上海 12 个区2,012条中小河道, 区域面 积 $855 \mathrm{~km}^{2}$ (陈一申等, 1997)。由于上海早期的城市 建设均在苏州河干流沿岸展开, 因此苏州河被誉为 上海的“母亲河”。苏州河曾有过水质清澈、鱼虾丰 富的历史, “吴淞江垂钧” 曾是清朝末年上海的十景 之一。但自1920年起, 上海市区段开始出现季节性 水质恶化, 50-60年代污染加重, 到70年代末上海段 全线遭受污染，市区河段终年黑臭(张广强等, 2009), 成为一条典型的城市污染河道。

从 20 世纪 90 年代后期以来, 上海市实施了三期 苏州河环境综合整治工程。一期工程(1999-2003年) 以消除苏州河干流黑臭以及与黄浦江交汇处“黑黄” 界面、整治两岸脏乱环境和改善滨河面貌为目标, 二期工程(2003-2005年)以稳定苏州河干流水质、改 善陆域环境为目标, 三期工程(2006-2011年)以持续 改善苏州河干流和支流的水质为目标, 为生态系统 的恢复创造条件(赵敏华和龚屹巍, 2018)。对照上海 建设卓越全球城市的要求, 上海市2019年启动了第 四期苏州河环境综合整治工程, 计划 4 年内投入资 金254亿元，全面消除劣 $\mathrm{V}$ 类水体，提高防洪能力, 提升生态环境质量(季永兴和刘水芹, 2020)。

随着水环境污染状况的日益加剧, 对水生态安 全的监测及预警预报成为迫切的需求。水生生物环
境监测作为有效的水质环境监测评估和预警手段 也得到广泛应用和快速发展, 鱼类、底栖动物、浮 游生物和着生生物等成为常用的指示生物(Beugly \& Pyron, 2010; 戴舒雅等, 2013; Sá-Oliveira et al, 2015; 张述伟等, 2015; 刘焕章等, 2016)。已有对苏州河浮 游植物、底栖动物和着生生物群落的相关研究, 阐述 了这些类群与水质变化的一些对偶关系(廖祖荷和顾 泳洁, 2003; 程曦等, 2009; 刘冬燕等, 2009)。

本世纪以前, 仅 《上海鱼类志》 (中国水产科学 研究院东海水产研究所和上海市水产研究所, 1990) 中对苏州河鱼类有一些零星记载。随着苏州河环境 综合整治工程的开展, 鱼类的跟踪调查日益增多。 2001年, 夏建宏等(2009)采集了苏州河10个断面的 鱼类样本, 记录鱼类43种; 2006年, 陈小华等(2008) 对苏州河上游 2 个断面的鱼类样本作了分析, 记录 鱼类28种。本研究旨在通过全面而深入的样本采集, 分析鱼类物种多样性及群落结构现状, 阐明苏州河 综合整治工程开始以来鱼类物种多样性的变化, 为 进一步整治提供生态学参考。

\section{材料与方法}

\section{1 采集断面的设置}

结合河流形态、水文特点以及水质监测的历史 习惯, 在苏州河设置13个采样断面, 其中干流10个, 即赵屯(S1)、白鹤(S2)、黄渡(S5)、封浜河口(S7)、 北新泾(S8)、中山西路桥(S9)、武宁路桥(S10)、昌 化路桥(S11)、成都路桥(S12)、外白渡桥(S13); 支流 


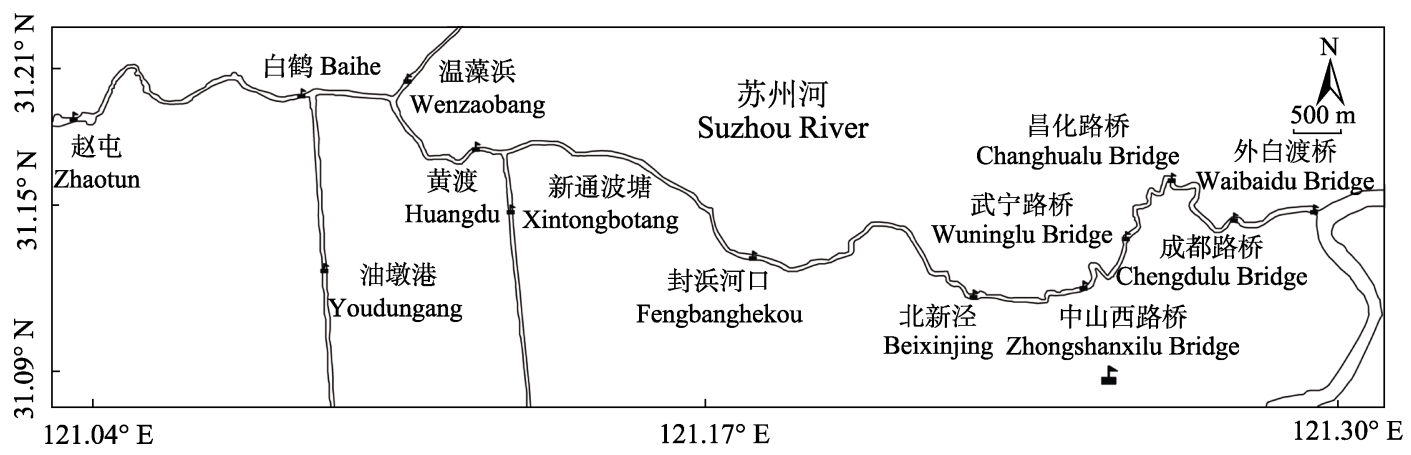

图1 上海苏州河各采样断面示意图

Fig. 1 Collecting sites of the Suzhou River in Shanghai

\section{表 1 上海苏州河各采样断面位置信息表}

Table 1 The coordinates of sections of the Suzhou River in Shanghai

\begin{tabular}{lll}
\hline $\begin{array}{l}\text { 代号 } \\
\text { Codes }\end{array}$ & $\begin{array}{l}\text { 断面名称 } \\
\text { Section names }\end{array}$ & $\begin{array}{l}\text { 中心经纬度 } \\
\text { Coordinates }\end{array}$ \\
\hline 上游 Upstream & \\
S1 & 赵屯 Zhaotun & $121^{\circ} 04^{\prime} \mathrm{E}, 31^{\circ} 16^{\prime} \mathrm{N}$ \\
S2 & 白鹤 Baihe & $121^{\circ} 08^{\prime} \mathrm{E}, 31^{\circ} 16^{\prime} \mathrm{N}$ \\
S3 & 油墩港 Youdungang & $121^{\circ} 09^{\prime} \mathrm{E}, 31^{\circ} 14^{\prime} \mathrm{N}$ \\
S4 & 蕰藻浜 Wenzaobang & $121^{\circ} 12^{\prime} \mathrm{E}, 31^{\circ} 18^{\prime} \mathrm{N}$ \\
S5 & 黄渡 Huangdu & $121^{\circ} 12^{\prime} \mathrm{E}, 31^{\circ} 15^{\prime} \mathrm{N}$ \\
S6 & 新通波塘 Xintongbotang & $121^{\circ} 12^{\prime} \mathrm{E}, 31^{\circ} 14^{\prime} \mathrm{N}$ \\
S7 & 封浜河口 Fengbanghekou & $121^{\circ} 18^{\prime} \mathrm{E}, 31^{\circ} 13^{\prime} \mathrm{N}$ \\
S8 & 北新泾 Beixinjing & $121^{\circ} 22^{\prime} \mathrm{E}, 31^{\circ} 13^{\prime} \mathrm{N}$ \\
下游 Downstream & \\
S9 & 中山西路桥 Zhongshanxilu Bridge & $121^{\circ} 23^{\prime} \mathrm{E}, 31^{\circ} 13^{\prime} \mathrm{N}$ \\
S10 & 武宁路桥 Wuninglu Bridge & $121^{\circ} 25^{\prime} \mathrm{E}, 31^{\circ} 14^{\prime} \mathrm{N}$ \\
S11 & 昌化路桥 Changhualu Bridge & $121^{\circ} 26^{\prime} \mathrm{E}, 31^{\circ} 15^{\prime} \mathrm{N}$ \\
S12 & 成都路桥 Chengdulu Bridge & $121^{\circ} 27^{\prime} \mathrm{E}, 31^{\circ} 14^{\prime} \mathrm{N}$ \\
S13 & 外白渡桥 Waibaidu Bridge & $121^{\circ} 29^{\prime} \mathrm{E}, 31^{\circ} 14^{\prime} \mathrm{N}$ \\
\hline
\end{tabular}

3 个, 即油墩港(S3)、蕰藻浜(S4)、新通波塘(S6), 具 体位置见图1和表1。一般以北新泾为界, 将苏州河 分为上游河段和下游河段。

\section{2 鱼类样本采集方法}

2019年6月4-23日(夏季)和2019年9月14-26日 (秋季), 租用专业渔船在苏州河13个采样断面对鱼 类样本进行了2次采集。同一次采集期间, 气温和风 力接近, 都为晴或多云天气, 以消除天气对采样的 影响。在每个断面的 $200 \mathrm{~m}$ 左右河道范围内, 定量和 定性采集标本。

\subsection{1 定量样本}

每一个断面均采用地笼网和三层刺网进行采 样, 地笼网主要用于采集底层鱼类, 三层刺网可以
采集全水层鱼类。地笼网由中间 10 节笼体和 2 个尾 稍组成，拉伸后长度为 $7 \mathrm{~m}$; 每节笼体长宽高为 $0.5 \mathrm{~m} \times 0.4 \mathrm{~m} \times 0.4 \mathrm{~m}$, 两侧各设 1 个进口, 两条底 纲加石子坠, 上纲各伸出 $14 \mathrm{~cm}$ 的翅; 尾稍长各 $1 \mathrm{~m}$, 网目均为 $10 \mathrm{~mm}$ 。在离岸 $15-20 \mathrm{~m}$ 的水域, 垂直河岸, 间隔20 m平行放置8-10条, 由于水上交通限制，中 山西路桥及以下断面放置4-6 h, 以上断面放置 $10 \mathrm{~h}$ 左右。三层刺网规格为 $1.5 \mathrm{~m} \times 30 \mathrm{~m}$, 网目内层 $15 \mathrm{~mm}$, 外层30 mm。在沿岸缓流处放置10-12条, 由于航运 和漂浮物的干扰，保证回收时下游段有 4 条、上游段 有6条以上的有效采集网具，采集时间为 $2-6 \mathrm{~h}$ 。

\subsection{2 定性样本}

定量采集的同时，在每个断面用小型地笼网和 撒网进行定性采集, 以弥补定量样本采集物种的可 能遗漏。小型地笼网的结构略有不同，中间 10 节笼 体的长宽高为 $0.4 \mathrm{~m} \times 0.3 \mathrm{~m} \times 0.3 \mathrm{~m}$, 每节设 1 个进 口，底部加石子队坠，上纲无翅，尾稍长 $0.5 \mathrm{~m}$, 全网 拉伸长 $5 \mathrm{~m}$, 网目 $5 \mathrm{~mm}$ 。将30-40条网具放在各类小 生境中采集。撒网的规格为口径 $5 \mathrm{~m}$ 、网长 $5 \mathrm{~m}$ 、网 目 $20 \mathrm{~mm}$, 每个采样断面撒网10次以上。

\section{3 样本保存和鉴定}

采集的样本用 $10 \%$ 的福尔马林固定，每个断面 的每一种网具样本分别保存，集中带回实验室鉴 定。物种鉴定及生态特征分类主要依据《中国鱼类 系统检索》(成庆泰和郑葆珊, 1987)、《上海鱼类志》 (中国水产科学研究院东海水产研究所和上海市水 产研究所, 1990)和《江苏鱼类志》(倪勇和伍汉霖, 2006)等, 目、科等高级阶元依Fishes of the World (Nelson et al, 2016)。鉴定好的标本用电子天平称量, 体重精度为 $0.1 \mathrm{~g}$, 游标卡尺或量鱼板测量体长, 精 度为 $1 \mathrm{~mm}$ 。记录每个采样断面、每种网具的鱼类种 
类、数量和重量。

\section{4 生态类群划分}

按照唐文乔等(2003), 本文将苏州河鱼类生态 类型分为洄游性、河口性和淡水性; 营养结构分为 肉食性、植食性和杂食性; 栖息水层分为中上层、 中下层和底层; 体型大小分为大型、中型和小型。

\section{5 数据分析}

\subsection{1 物种优势度及多样性}

采用Pinkas相对重要性指数 (relative importance index, IRI)、Shannon-Wiener多样性指数 $\left(H^{\prime}\right)$ 、Pielou 均匀度指数 $(J)$ 、 Margalef种类丰富度指数 $(D)$ 、 Simpson优势度指数 $(C)$ 分析物种优势度及其多样性 (林龙山等, 2012)。IRI计算公式为:

$$
I R I=\left(W_{\mathrm{i}}+N_{\mathrm{i}}\right) \times F_{\mathrm{i}}
$$

式中, $W_{\mathrm{i}}$ 为某一物种的重量比 $(\%), N_{\mathrm{i}}$ 为该物种的数 量比(\%), $F_{\mathrm{i}}$ 为该物种在样本中的出现频率 $(\%)$ 。定义 $I R I \geq 1,000$ 的物种为优势种, $100 \leq I R I<1,000$ 的物 种为常见种, $10 \leq I R I<100$ 的物种为一般种, $I R I<$ 10 的物种为少见种(程济生和俞连福, 2004)。

$$
\begin{aligned}
& H^{\prime}=-\Sigma P_{i} \ln P_{i} \\
& J=H^{\prime} / \ln S \\
& D=(S-1) / \ln N \\
& C=1-\Sigma\left(P_{i}\right)^{2}
\end{aligned}
$$

式中, $S$ 为物种数, $N$ 为所有种类的总个体数, $P_{i}$ 为第 $i$ 种个体在全部个体中的比例。

\subsection{2 丰度生物量曲线}

丰度生物量曲线 (abundance-biomass comparison curve, 简称 $A B C$ 曲线)最初用于污染对大型海 洋底栖动物群落的影响监测(Warwick, 1986), 随后 扩展到由污染引起的人为变化对游泳动物群落的 影响监测(Chiu \& Kuo, 2012), 也可以反映鱼类群落 中种类组成的变化情况以及受干扰的程度(李圣法, 2008)。ABC曲线的统计量用 $W$ 表示, 公式为:

$$
W=\sum_{i=1}^{s} \frac{\left(W_{i}-N_{i}\right)}{50(S-1)}
$$

式中, $W_{i}$ 和 $N_{i}$ 为 $\mathrm{ABC}$ 曲线中种类序号对应的生物量 和丰度的累积百分比。

\subsection{3 群落结构特征}

以鱼类种类和数量组成原始的数据矩阵, 样本 为采样的 13 个断面, 变量为各断面每种鱼的数量百
分比。以Bray-Curtis相似性系数为基础构建断面之 间的相似性矩阵，建立聚类分析(Cluster)图和非参 数多维标度排序 (non-metric multidimensional scaling, nMDS)平面图(Clarke \& Warwick, 2001; Lozupone \& Knight, 2005)。根据胁强系数(stress)检 验nMDS分析结果的优劣: Stress $<0.05$ 时拟合极好; $0.05 \leq$ Stress $<0.1$ 时拟合较好; $0.1 \leq$ Stress $<0.2$ 时 拟合一般; $0.2 \leq$ Stress $<0.3$ 时拟合较差(王卓等, 2019)。运用相似性分析(ANOSIM)检验类群之间的 差异显著性，应用Simper分析每种鱼对群落组内相 似性和组间相异性的平均贡献率。为提高数据的正 态性和方差齐性，降低极端数值的负面影响，对原 始数据矩阵进行开四次方根转换, 并且只对鱼类数 量百分比大于 $1 \%$ 的种类进行聚类和排序分析。

\section{6 统计分析}

采用PRIMER 5.0软件进行ABC、Cluster、 nMDS、Simper和Anosim分析，并使用SPSS 19.0、 Excel 2010、Vision 2010和Photoshop CS6绘图。

\section{结果}

\section{1 种类组成}

定量和定性采集鱼类 10,102 尾，隶属于 8 目 15 科37属45种(附录1)。其中, 鲤形目有2科19属24种, 占总种数的 $53.33 \%$; 鲇形目 6 科 9 属 10 种; 鲇形目 2 科2属4种; 合鳃鱼目2科 2 属2种; 鲻形目1科2属2种; 鲱形目、鳗鲭目、领针鱼目各1科1属1种(图2a)。从 生态类型看，洄游性鱼类有 2 种，即刀鲚 (Coilia nasus)和鳗鲟(Anguilla japonica); 河口性5种, 即鲻 (Mugil cephalus)、鮻(Liza haematocheilus)、花鲈 (Lateolabrax japonicus)、纹缟虾虎鱼(Tridentiger trigonocephalus) 和拉氏狼牙虾虎鱼 (Odontamblyopus lacepedii); 其余38种均为淡水鱼类。从营养 结构、栖息水层和体型大小看(图2b), 苏州河鱼类以 肉食性、底层的中小型鱼类为主。

\section{2 物种优势度的季节变化}

在定量样本中, 夏季上游有鱼类26种, 其中优 势种 (表 2) 有似鳊 (Pseudobrama simoni)、粲 (Hemiculter leucisculus)、贝氏徐(H. bleekeri)和兴凯 䁤 (Acheilognathus chankaensis), 合计占种数的 $15.38 \%$ 、个体数的 $78.88 \%$ 、总重量的 $76.83 \%$, 常见 种 8 种, 一般种 6 种, 少见种 8 种; 下游有鱼类 11 种, 
优势种有鲫(Carassius auratus)、泥鳅(Misgurnus anguillicaudatus)和乌鳢(Channa argus), 合计占种 数的 $27.27 \%$ 、个体数的 $91.43 \%$ 、重量的 $97.28 \%$, 常 见种1种，一般种6种，少见种1种。

秋季上游有鱼类 22 种, 优势种有似鳊、鲫和刀 鲚, 合计占种数的 $13.64 \%$ 、个体数的 $75.02 \%$ 、重量 的 $84.09 \%$, 常见种 9 种，一般种 4 种，少见种 6 种; 下 游有鱼类15种, 优势种有鲫、泥鳅和鲤(Cyprinus carpio), 合计占种数的 $20 \%$ 、个体数的 $68.09 \%$ 、重 量的 $82 \%$, 常见种 4 种，一般种 7 种，少见种 1 种。

夏季和秋季上游共同的优势种为似鳊, 且为两 季的绝对优势种, 其 $I R I$ 值分别为 $10,159.54$ 和 11,302.52, 远高于其他种类; 下游共同的优势种为 鲫和泥鳅, 两者都属于两季的绝对优势种。

\section{3 物种多样性指数的季节差异}

利用定量样本分析了苏州河各采样断面4类物
种多样性指数的季节差异(图3)。从全河段看, 夏季 Shannon-Wiener多样性指数 $(H)$ 、Pielou均匀度指数 $(J) 、$ Simpson优势度指数 $(C)$ 和Margalef丰富度指数 $(D)$ 的平均值分别为 $1.27(0.34-2.02) 、 0.59(0.21-$ $0.91) 、 0.57$ (0.13-0.83)和1.77 (0.56-2.80), 均小于相 应的秋季平均值 $1.48(0.58-2.12) 、 0.67(0.21-0.86)$ 、 $0.66(0.22-0.82)$ 和1.92 (1.00-3.14)。

分河段看, 北新泾以上的上游河段, 夏季多样 性指数 $\left(H^{\prime}\right)$ 、种类丰富度指数 $(D)$ 和优势度指数 $(C)$ 普遍高于秋季, 北新泾以下的下游河段则是秋季高 于夏季。从具体的断面看, 夏秋两季从上游到下游, 多样性指数 $\left(H^{\prime}\right)$ 、种类丰富度指数 $(D)$ 和优势度指数 (C)均呈逐渐降低的趋势, 说明上游鱼类群落结构 相对稳定, 物种相对丰富。而均匀度指数 $(J)$ 的波动 性较大, 缺乏明显的时空变化规律(图3)。

a 分类学组成 Taxonomic composition

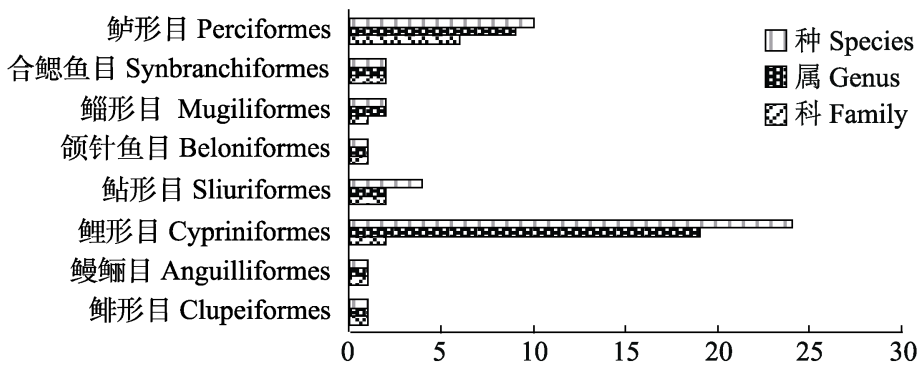

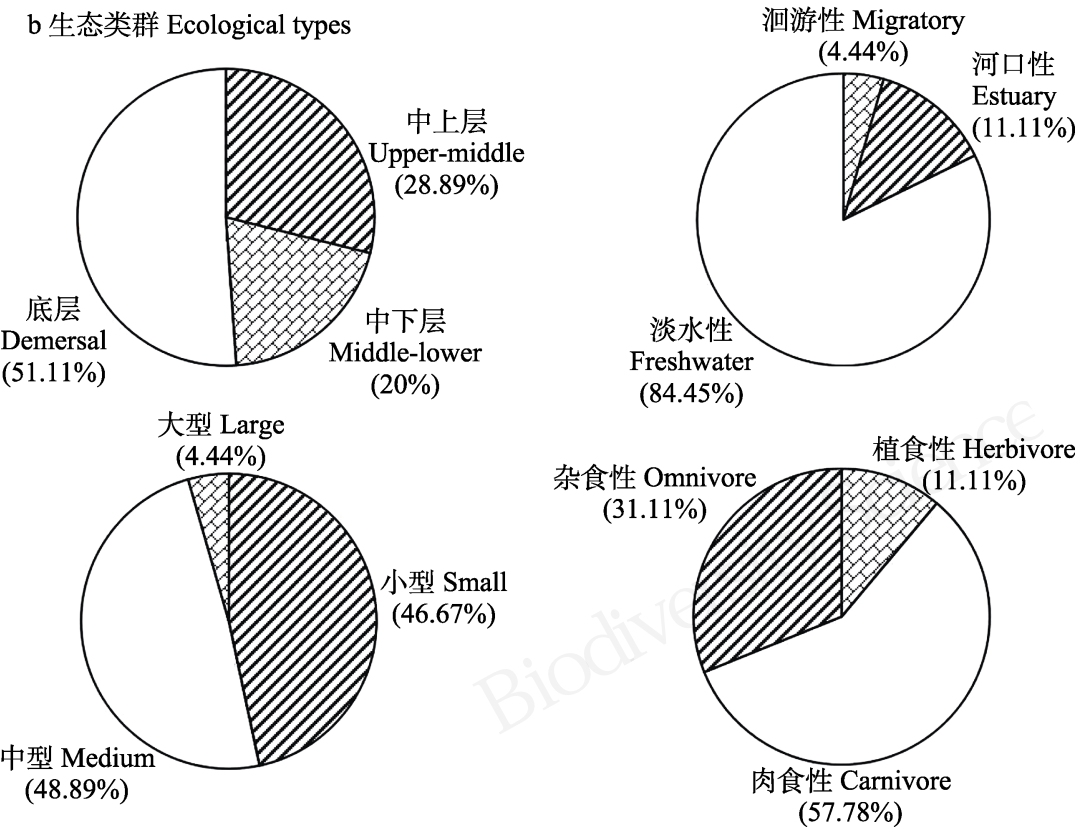

图2 上海苏州河鱼类组成

Fig. 2 Fish species composition of the Suzhou River in Shanghai 
表2 上海苏州河鱼类优势种 $(I R I \geq 1,000)$ 和常见种 $(100 \leq I R I<1,000)$ 的相对重要性指数

Table 2 Index of relative importance $(I R I)$ of the dominant $(I R I \geq 1,000)$ and common $(100 \leq I R I<1,000)$ fish species of the Suzhou River in Shanghai

\begin{tabular}{|c|c|c|c|c|}
\hline \multirow{2}{*}{ 种类 Species } & \multicolumn{2}{|l|}{ 夏季 Summer } & \multicolumn{2}{|l|}{ 秋季 Autumn } \\
\hline & 上游 Upstream & 下游 Downstream & 上游 Upstream & 下游 Downstream \\
\hline 刀鲚 Coilia nasus & & & $1,045.89$ & 154.59 \\
\hline 尧嘴鲌 Culter alburnus & & & 130.01 & \\
\hline 达氏鲌 Culter dabryi & 920.05 & & 827.64 & \\
\hline 红鯺原鲌 Cultrichthys erythropterus & 454.52 & & 109.75 & \\
\hline 贝氏粲 Hemiculter bleekeri & $1,116.50$ & & 139.41 & \\
\hline 粲 Hemiculter leucisculus & $2,898.83$ & & 183.99 & \\
\hline 似鳊 Pseudobrama simoni & $10,159.54$ & 309.94 & $11,302.52$ & 756.94 \\
\hline 麦穗鱼 Pseudorasbora parva & 391.31 & & 244.64 & \\
\hline 兴凯鱊 Acheilognathus chankaensis & $1,024.73$ & & 976.12 & \\
\hline 大鳍鱊 Acheilognathus macropterus & & & 215.51 & \\
\hline 高体鳑鲏 Rhodeus ocellatus & 274.22 & & & \\
\hline 鲫 Carassius auratus & 549.44 & $6,752.95$ & $1,798.81$ & $7,029.52$ \\
\hline 鲤 Cyprinus carpio & & & & $1,666.27$ \\
\hline 泥鳅 Misgurnus anguillicaudatus & 167.30 & $5,946.77$ & 264.08 & $5,202.53$ \\
\hline 光泽黄颡鱼 Pelteobagrus nitidus & 179.78 & & & 932.39 \\
\hline 子陵吻虾虎鱼 Rhinogobius giurinus & 182.71 & & & \\
\hline 乌鳢 Channa argus & & $1,334.40$ & & 765.65 \\
\hline
\end{tabular}

空白处为该季节 $I R I<100$ 的种类, 未列出具体数值。

The blank space show species with $I R I<100$ in this season, and the specific value is not listed.
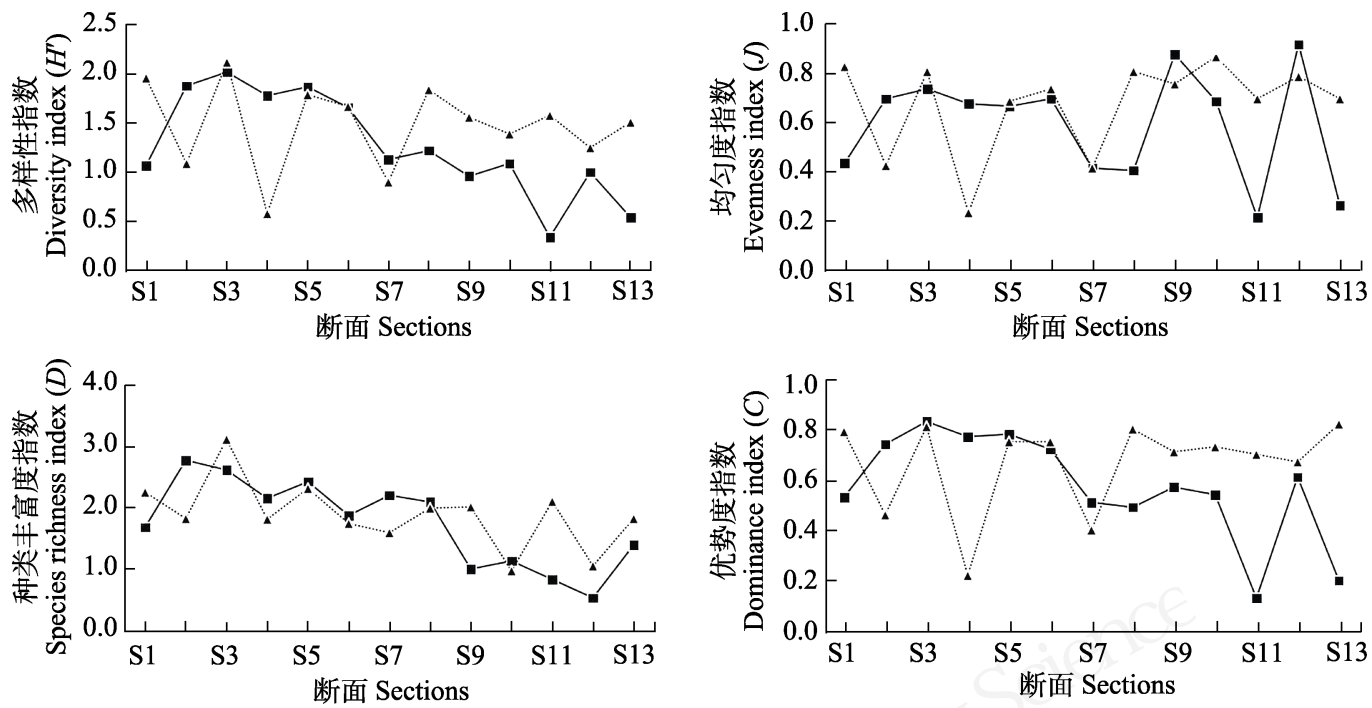

夏季 Summer ….... 秋季 Autumn

图3 上海苏州河鱼类多样性指数的季节变化。断面代号见表1。

Fig. 3 Seasonal changes of fish diversity index of the Suzhou River in Shanghai. Section codes see Table 1.

\section{$2.4 \mathrm{ABC}$ 曲线的特征}

根据定量样本, 对苏州河上游和下游的鱼类群 落分别作 $\mathrm{ABC}$ 曲线(图4)。夏季, 上游的 $W$ 为负值, 生物量与丰度优势度曲线走向接近且有多次交叉,
表明该水域的鱼类群落中以小型鱼类占主体(孙莎 莎等, 2013), 鱼类群落受到了严重干扰; 下游的 $W$ 值略大于 0 , 生物量优势度曲线总体位于丰度优势 度曲线之上, 起点也远高于后者, 但在第二优势种 


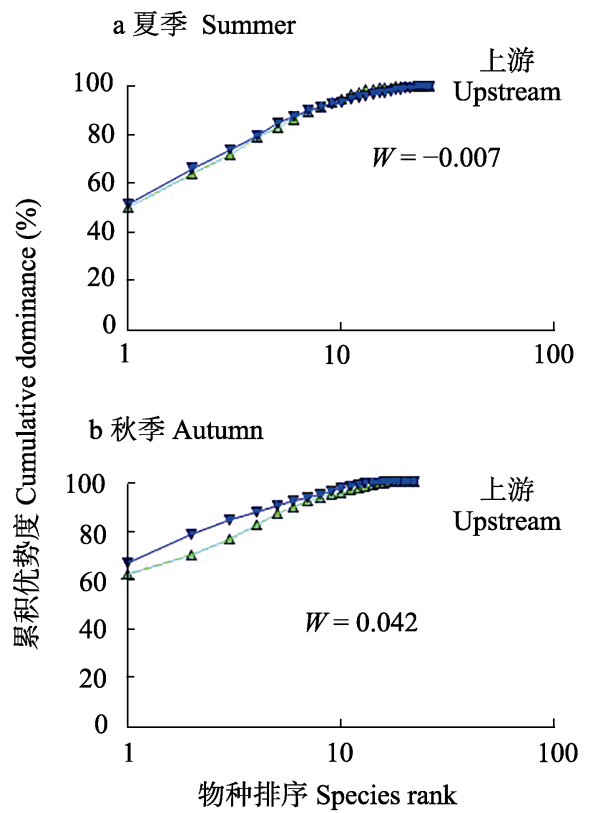

$\Delta$ 丰度 Abundance

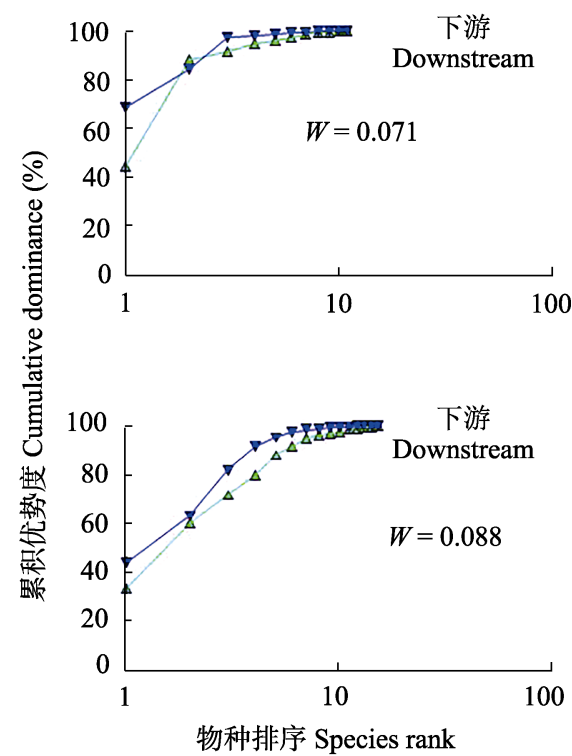

$\checkmark$ 生物量 Biomass

图4 上海苏州河夏季和秋季鱼类群落的丰度生物量曲线以及 $W$ 统计值

Fig. 4 ABC curves and $W$ values of fish assemblage of the Suzhou River in Shanghai in summer and autumn

处存在交叉, 表明第一优势种为个体均重大于群落 平均体重的鱼类, 第二优势种则为小型的 $r$ 对策鱼 类, 群落处于不稳定状态。

秋季, 上游的生物量优势度曲线始终位于丰度 优势度曲线之上, 表明鱼类群落结构相对稳定, 环 境干扰较少。但下游的 $\mathrm{ABC}$ 曲线走势与夏季类似, 鱼 类群落也处于相对不稳定状态, 受到较大的干扰。

\section{5 物种的空间分布及群落结构差异}

通过定量样本和定性样本的分析, 获得各断面 的物种数如图 5 。可以看出, 上游河段的种类较多, 最高的黄渡(S5)有33种, 最低的北新泾(S8)也有 18 种, 平均 25 种。下游河段的种类较少, 平均仅 10 种, 但靠近黄浦江的外白渡桥(S13)断面也有13种。与干 流相比, 3 个支流断面的种类相对较少, 油墩港 (S3)、蕰藻浜(S4)、新通波塘(S6)分别为 23 种、22种 和14种。

基于定量样本的鱼类数量百分比所作的Cluster 聚类分析显示(图6), Bray-Curtis相似性在17.03\%的 水平上, 可以将苏州河鱼类群落分为 $\mathrm{I} 、 \mathrm{II}$ 群组, 群 组 I 为 5 个上游干流断面和 3 个支流断面, 群组II为下 游5个断面。Anosim检验结果表明, 群组 I和群组 II 之间的差异极显著 $(R=0.988, P=0.001)$ 。 nMDS排 序分析的平均胁强系数为 0.06 , 结果可信。聚类分
析所得出的两个组在nMDS二维点阵排序图上也获 得了很好体现, 都能解释苏州河上游与下游鱼类群 落结构的明显差异性。

对上述分组进行Simper分析, 鱼类群组平均相 似性(相异性)贡献之和占 $90 \%$ 以上的特征种(分歧种) 见表3。群组I的平均相似性为 $59.73 \%$, 主要特征种 有似鳊、粲、兴凯䁤和达氏鲌(Culter dabryi)等, 似 鳊的贡献率最大。群组II的平均相似性为 $43.90 \%$, 主要特征种有泥鳅、鲫、似鳊和光泽黄颡鱼 (Pelteobagrus nitidus)等, 泥鳅的贡献率最大。群组 I-群组II的平均相异性为 $82.93 \%$, 主要分歧种包括 似鳊、泥鳅、鲫、光泽黄颡鱼和兴凯䁤等 11 种, 累

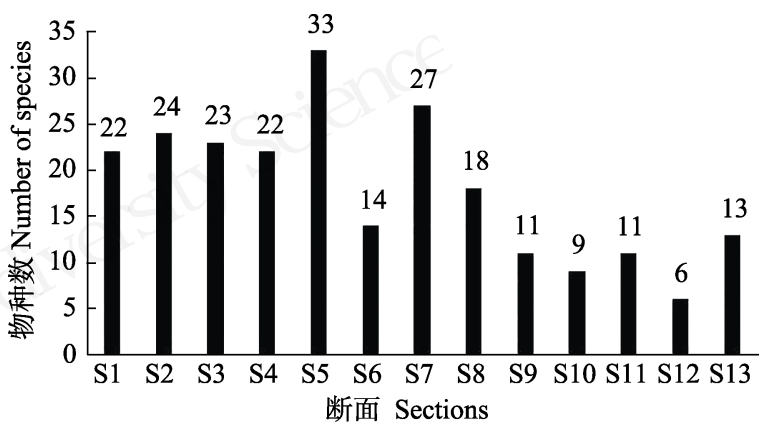

图5 上海苏州河鱼类物种的空间分布。断面代号见表1。 Fig. 5 Spatial distribution of fish species of the Suzhou River in Shanghai. Section codes see Table 1. 

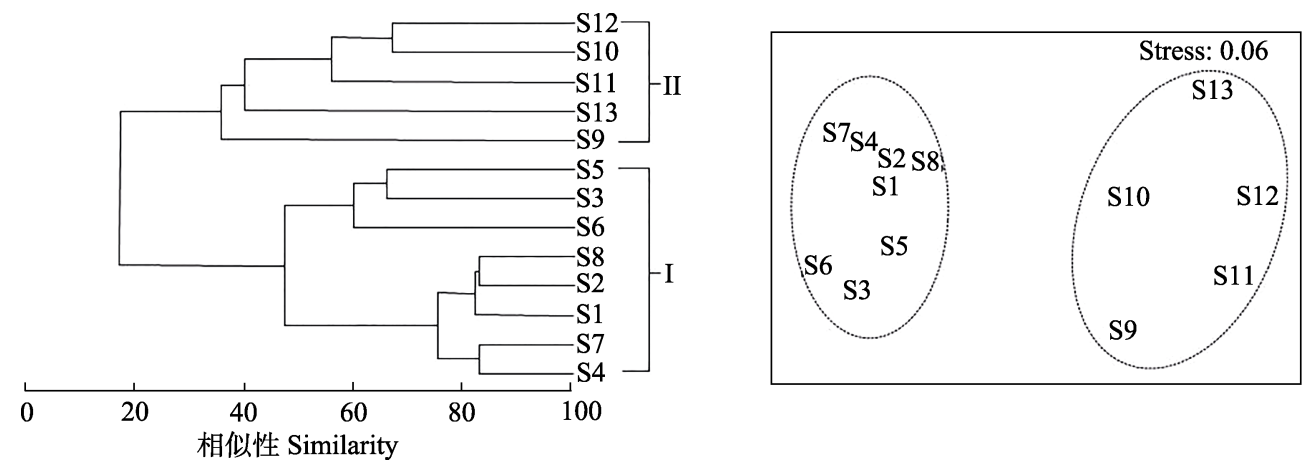

图6 上海苏州河鱼类群落聚类图和非参数多维标度排序图。断面代号见表1。

Fig. 6 The cluster and nMDS plots of fish assemblage of the Suzhou River in Shanghai. Section codes see Table 1.

表3 上海苏州河鱼类群组内相似性(或群组间相异性)贡献率之和占 $90 \%$ 以上的特征种(或分歧种)

Table 3 Fish characteristic species (or divergent species) with more than $90 \%$ of the total contribution rate of similarity within group (or dissimilarity between groups) of the Suzhou River in Shanghai

\begin{tabular}{|c|c|c|c|}
\hline \multirow[t]{2}{*}{ 种类 Species } & \multicolumn{2}{|c|}{$\begin{array}{l}\text { 平均相似性贡献率 } \\
\text { Average similarity contribution (\%) }\end{array}$} & \multirow{2}{*}{$\begin{array}{l}\text { 平均相异性贡献率 } \\
\text { Average dissimilarity contribution (\%) } \\
\text { 群组I-群组II Group I-Group II }\end{array}$} \\
\hline & 群组I Group I & 群组II Group II & \\
\hline 似鳊 Pseudobrama simoni & 66.34 & 4.43 & 26.37 \\
\hline 粲 Hemiculter leucisculus & 8.61 & & 4.65 \\
\hline 兴凯鱊 Acheilognathus chankaensis & 7.18 & & 5.63 \\
\hline 达氏鲌 Culter dabryi & 3.05 & & 2.62 \\
\hline 鲫 Carassius auratus & 2.58 & 34.68 & 15.62 \\
\hline 泥鳅 Misgurnus anguillicaudatus & & 47.65 & 21.45 \\
\hline 光泽黄颡鱼 Pelteobagrus nitidus & & 4.36 & 6.19 \\
\hline 麦穗鱼 Pseudorasbora parva & & & 2.67 \\
\hline 乌鳢 Channa argus & & & 2.43 \\
\hline 贝氏粲 Hemiculter bleekeri & & & 2.25 \\
\hline 鲤 Cyprinus carpio & & & 2.16 \\
\hline 不足1\% Less than 1\% & 4.23 & & \\
\hline 总计 Total & 91.99 & 91.12 & 92.04 \\
\hline 平均值 Average values & 59.73 & 43.90 & 82.93 \\
\hline
\end{tabular}

表中空白处为不属于前 $90 \%$ 范围内的物种, 未列出具体数值。

The blank spaces in the table show species that do not belong to the top $90 \%$, and specific values are not listed.

积对群组间平均相异性贡献率为 $92.04 \%$, 其中似鳊 的贡献率最大, 为 $26.37 \%$ 。

\section{3 讨论}

\section{1 苏州河治理过程中鱼类多样性的比较}

根据前人的研究报道(中国水产科学研究院东 海水产研究所和上海市水产研究所, 1990; 陈小华 等, 2008; 夏建宏等, 2009)及本研究, 苏州河历年记 录的鱼类有75种。苏州河整治过程中的前 2 次跟踪 调查, 2001年(夏建宏等, 2009)记录鱼类43种, 占总 种数的 $57.33 \% ; 2006$ 年(陈小华等, 2008)记录28种,
占 $37.33 \%$, 鱼类物种数呈下降趋势。本次调查记录 到鱼类 45 种, 占 $60.00 \%$, 较苏州河整治之前, 物种 数出现了明显的回升。水质监测数据也显示, 虽然 2007-2011年间水质有逐渐好转的趋势, 但2012年 又出现了恶化现象(丁义等, 2013), 表明前三期苏州 河整治并没有形成鱼类生存所需的稳定生态条件, 也表明鱼类物种多样性监测更能全面地反映水域 生态系统的健康状况。

图7展示了3次苏州河鱼类调查在各断面所采 集的鱼类种数, 可见历次调查均是北新泾 $\mathrm{S} 8$ 以上的 上游郊区河段种类较多, 下游中心城区河段的种类 


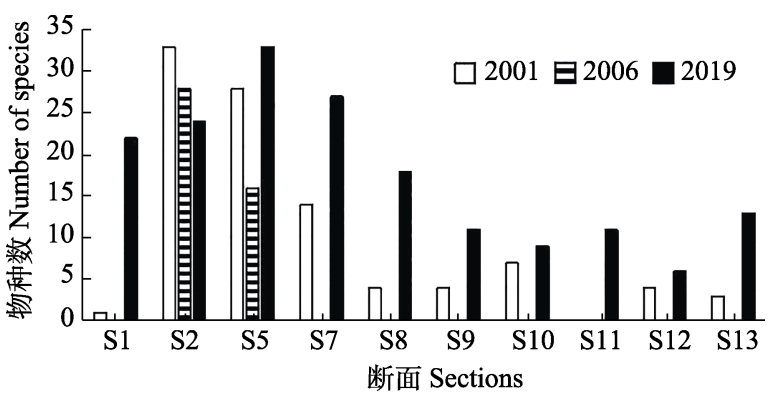

图7 上海苏州河各断面鱼类种类的历年变化。2001年数据 引自夏建宏等(2009); 2006年数据引自陈小华等(2008)。断面 代号见表1。

Fig. 7 Changes of fish species in different sections of Suzhou River in Shanghai over the years. Data for 2011 from Xia et al, 2009; Data for 2006 from Chen et al, 2008. Section codes see Table 1.

相对较少, 明显的水质差异和下游河道的渠化改造 可能是造成鱼类多样性差异的主要原因(陈一申等, 1997; 张广强等, 2009; Yan et al, 2010; 丁义等, 2013)。但本次调查发现下游河段的物种数有明显增 多的趋势, 5 个采样断面平均达 10 种, 与上游河段的 种类数差异有所缩小。这种上游鱼类向下游迁移的 趋势, 可能预示着中心城区和郊区河段的水质差别 正在缩小, 下游河段的水生态系统已出现明显的恢 复迹象。

\section{2 苏州河鱼类群落结构的现状}

物种多样性、优势种、等级聚类和 $\mathrm{ABC}$ 曲线等 常用来分析鱼类群落结构的现状 (Clarke \& Warwick, 2001; 程济生和俞连福, 2004; Sá-Oliveira et al, 2015)。本次调查发现，夏季和秋季上游鱼类均 为36种, 下游分别为 12 种和 15 种, 说明上游的物种 多样性季节变化不明显, 下游季节变化差异较大。 这可能与苏州河河口水闸的开启, 使某些栖息于黄 浦江的鱼类逆流进入苏州河下游有关，如在下游采 集到了河口性的鲻和鮻。但相对重要性指数(IRI)显 示, 上游优势种组成的季节性波动较大, 夏季为似 鳊、粲、贝氏粲和兴凯鱊, 而秋季为似鳊、鲫和刀 鲚, 似鳊是两季的绝对优势种。相反, 下游的季节 性波动较小, 优势种均以鲫和泥鳅为主。这种优势 种通常由 1 个或少数几个种类组成的群落, 一般存 在于干扰因素较多的河流生境中(Prista et al, 2003)。

Cluster聚类和nMDS排序分析表明，苏州河鱼 类群落可以分为上游及其支流与下游断面 2 个群 组。Simper分析显示, 群组I的平均相似性(59.73\%) 明显高于群组II (43.90\%), 说明上游各断面间的相
似程度比下游高(汪振华等, 2011; Chen et al, 2018; 郑亦婷等, 2019)。两群组之间除种类数不同外, 特 征种也有很大差异。群组I的主要特征种为似鳊、粲、 兴凯䁤和达氏鲌等, 似鳊的贡献率最大。群组II的主 要特征种为泥鱾、鲫、似鳊和光泽黄颞鱼等, 泥鱾 的贡献率最大。似鳊、泥鳅、鲫、光泽黄颡鱼和兴 凯鮦等是造成群组I和群组II差异性的主要分歧种。

$\mathrm{ABC}$ 曲线也可反映出上游鱼类群落以小型鱼 类占主体，下游鱼类群落的第一优势种则为个体均 重较大的种类。同时, 从 $W$ 值接近于 0 的分析结果看, 苏州河鱼类群落结构总体上并不稳定，环境干扰较 大(李圣法, 2008; 孙莎莎等, 2013)。特别是夏季的 下游, 第一优势种鲫的生物量优势度曲线起点远高 于丰度优势度曲线之上，而第二优势种泥鳅的这 2 类曲线则相反，表明这 2 个种受到了严重的人为干 扰。近年慈善放生活动较多, 主要种类为鲫、泥鳅、 鲤、乌鳢和黄鳝(Monopterus albus)等, 并且夏汛期 暴雨冲刷使得城区污染物大量溢入苏州河，这二者 可能是主要原因。季节变化产生的一些水文特征如 水温和流量等变化, 影响着鱼类的索饵、产卵和越 冬等行为, 本身也会造成季节性的鱼类群落结构差 异(Beugly \& Pyron, 2010; Sá-Oliveira et al, 2015)。

\section{3 苏州河治理过程中指示鱼类的篮选}

鱼类是水域生态系统中高度可见且最具经济 价值的组成部分, 处于水生食物链的顶端。由于生 活史相对较长、对水环境改变反应敏感，几乎对所 有类型的人为干扰都有响应，能较全面地反映水环 境的整体健康状态和水污染的综合生物学效应，对 水域生态系统的变化趋势具有重要的指示价值, 被 广泛用于水污染的生物监测(Beugly \& Pyron, 2010; 戴舒雅等, 2013; Sá-Oliveira et al, 2015; 张述伟等, 2015; 刘焕章等, 2016)。

根据苏州河现有的鱼类种类及其生物学特征, 理想的敏感指示鱼类应具有以下特征: (1)自然种群, 没有放流个体; (2)全河段都有分布; (3)游泳能力较 强, 足以抵御水流的流动力; (4)生态学特征明确; (5) 种群数量较大; (6)对环境压力敏感; (7)易于采集 等。在苏州河上游广泛分布的翘嘴鲌 (Culter alburnus)、红鯺原鲌(Cultrichthys erythropterus)、棒 花鱼 (Abbottina rivularis)、子陵吻虾虎鱼 (Rhinogobius giurinus)等符合上述特征指标，但目 前还没有在下游出现。我们认为, 第四期苏州河环 
境整治的目标, 除了进一步改善水质, 还应将这些 鱼类的出现作为生态环境质量提升的标志之一。同 时, 下游河段鱼类多样性的增加以及上下游鱼类群 落结构之间差异程度的缩小, 标志着上下游河段水 质的一致性和生态条件的连通性，是更全面的鱼类 多样性指标。在苏州河整治过程中，也应定期监测 和评估这些指标。

致谢: 赵振官实验师、龚珑博士及倪健夫、刘思琪、 郡严、邓彦等研究生参加野外采集，汤琳教授、吴 阿娜教授和龚珑博士帮助课题设计, 特此致谢!

\section{ORCID}

余宏昌 (D) https://orcid.org/0000-0002-7072-1204

毕宝帅 (iD https://orcid.org/0000-0002-8207-3048

唐文乔 (iD) https://orcid.org/0000-0001-5992-5022

张亚 (D) https://orcid.org/0000-0002-2942-286X

郭弘艺 (ID) https://orcid.org/0000-0001-9338-731X

\section{参考文献}

Beugly J, Pyron M (2010) Temporal and spatial variation in the long-term functional organization of fish assemblages in a large river. Hydrobiologia, 654, 215-226.

Chen XH, Li XP, Cheng X (2008) Spatial-temporal distribution of fish assemblages in the upstreams of Huangpu River and Suzhou Creek. Biodiversity Science, 16, 191-196. (in Chinese with English abstract) [陈小华, 李小平, 程䂀 (2008) 黄浦江和苏州河上游鱼类多样性组成的时空特 征. 生物多样性, 16, 191-196.]

Chen YL, Shan XJ, Jin XS, Arne J, Yang T, Dai FQ (2018) Changes in fish diversity and community structure in the central and southern Yellow Sea from 2003 to 2015. Journal of Oceanology and Limnology, 36, 805-817.

Chen YS, Wu GH, Huang JT (1997) Analysis on current status of Suzhou Creek pollution. Shanghai Environmental Science, 16(1), 11-14. (in Chinese with English abstract) [陈一申, 吴国豪, 黄解田 (1997) 苏州河水环境污染现 状分析. 上海环境科学, 16(1), 11-14.]

Cheng JS, Yu LF (2004) The change of structure and diversity of demersal fish communities in the Yellow Sea and East China Sea in winter. Journal of Fisheries of China, 28, 29-34. (in Chinese with English abstract) [程济生, 俞连福 (2004) 黄、东海冬季底层鱼类群落结构及多样性变化. 水产学报, 28, 29-34.]

Cheng QT, Zheng BS (1987) Systematic Synopsis of Chinese Fishes. Science Press, Beijing. (in Chinese) [成庆泰, 郑葆 珊 (1987) 中国鱼类系统检索. 科学出版社, 北京.]

Cheng X, Li XP, Chen XH (2009) An assessment of long-term changes in water quality and benthos community of Suzhou Creek (1996-2006). Acta Ecologica Sinica, 29, 3278-3287. (in Chinese with English abstract) [程䂀, 李小平, 陈小华 (2009) 苏州河水质和底栖动物群落1996-2006年的时空 变化. 生态学报, 29, 3278-3287.]

Chiu MC, Kuo MH (2012) Application of $r / k$ selection to macroinvertebrate responses to extreme floods. Ecological Entomology, 37, 145-154.

Clarke KR, Warwick RM (2001) Change in Marine Communities: An Approach to Statistical Analysis and Interpretation, 2nd edn. PRIMER-E Ltd., Plymouth.

Dai SY, Yu J, Ding B, Yin WQ (2013) Application and developmental tendency of biomonitoring in water environmental monitoring. Pollution Control Technology, 26(5), 62-65, 71. (in Chinese with English abstract) [戴舒 雅，余俭，丁波，殷伟庆 (2013) 生物监测在水环境监测 中的应用及发展趋势. 污染防治技术, 26(5), 62-65, 71.]

Ding Y, Sun ZZ, Zhang YP, Lin HS, Hong B, Qi JY, Zhao R, Zhang D (2013) Analysis and assessment of long-term changes in water quality of Suzhou River (2007-2012). Fisheries Science and Technology Information, 40, 199-203. (in Chinese) [丁义, 孙振中, 张玉平, 林惠山, 洪波，戚隽渊，赵冉，张丹 (2013) 2007-2012年苏州河水 质变化分析与评价. 水产科技情报, 40, 199-203.]

East China Sea Fisheries Research Institute, Chinese Academy of Fishery Sciences, Shanghai Fisheries Research Institute (1990) Fishes of Shanghai. Shanghai Science and Technology Press, Shanghai. (in Chinese) [中国水产科学研 究院东海水产研究所, 上海市水产研究所 (1990) 上海 鱼类志. 上海科学技术出版社, 上海.]

Ji YX, Liu SQ (2020) Review and prospect of Suzhou Creek water environment treatment in 20 years. Water Resources Protection, 36(1), 25-30, 51. (in Chinese with English abstract) [季永兴, 刘水芹 (2020) 苏州河水环境治理20 年回顾与展望. 水资源保护, 36(1), 25-30, 51.]

Li SF (2008) Status of fish community in East China Sea using the method of abundance-biomass comparison (ABC) curve. Journal of Fishery Sciences of China, 15, 136-143. (in Chinese with English abstract) [李圣法 (2008) 以数量生 物量比较曲线评价东海鱼类群落的状况. 中国水产科学, 15, 136-143.]

Liao ZH, Gu YJ (2003) The relationship between periphytic biology communities and water quality in Suzhou River. Journal of East China Normal University (Natural Science), (3), 109-112. (in Chinese with English abstract) [廖祖荷, 顾泳洁 (2003) 苏州河着生生物群落结构的变化与水质 的关系. 华东师范大学学报(自然科学版), (3), 109-112.]

Lin LS, Zhao GG, Li Y, Gao TX, Zhang J (2012) Diversity of nekton in Dongshan Bay and adjacent areas. Acta Hydrobiologica Sinica, 36, 1119-1127. (in Chinese with English abstract) [林龙山, 赵贵根, 李渊, 高天翔, 张静 (2012) 东山湾及其邻近海域游泳动物多样性的分析. 水 生生物学报, 36, 1119-1127.]

Liu DY, Lin WP, Zhao M (2009) Community structural characteristics of phytoplankton in Suzhou Creek. Resources and Environment in the Yangtze Basin, 18, 914-918. (in Chinese with English abstract) [刘冬燕, 林文鹏, 赵敏 
(2009) 苏州河浮游植物群落结构特征. 长江流域资源与 环境, 18, 914-918.]

Liu HZ, Yang JX, Liu SW, Gao X, Chen YS, Zhang CG, Zhao K, Li XH, Liu W (2016) Theory and methods on fish diversity monitoring with an introduction to the inland water fish diversity observation in China. Biodiversity Science, 24, 1227-1233. (in Chinese with English abstract) [刘焕章, 杨 君兴, 刘淑伟, 高欣, 陈宇顺, 张春光, 赵凯, 李新辉, 刘 伟 (2016) 鱼类多样性监测的理论方法及中国内陆水体 鱼类多样性监测. 生物多样性, 24, 1227-1233.]

Lozupone C, Knight R (2005) UniFrac: A new phylogenetic method for comparing microbial communities. Applied and Environmental Microbiology, 71, 8228-8235.

Nelson JS, Grande TC, Wilson MVH (2016) Fishes of the World, 5th edn. Wiley, New York.

Ni Y, Wu HL (2006) Fishes of the Jiangsu Province. China Agriculture Press, Beijing. (in Chinese) [倪勇, 伍汉霖 (2006) 江苏鱼类志. 中国农业出版社, 北京.]

Prista N, Vasconcelos RP, Costa MJ (2003) The demersal fish assemblage of the coastal area adjacent to the Tagus: Relationships with environmental conditions. Acta Oceanologica, 26, 525-536.

Sá-Oliveira JC, Isaac VJ, Ferrari SF (2015) Fish community structure as an indicator of the long-term effects of the damming of an Amazonian river. Environmental Biology of Fishes, 98, 273-286.

Sun SS, Tang WQ, Guo HY, Li HH, Liu D, Zhou TS, Chen HZ, Shen LH, Gu SX (2013) Composition and changes in abundance and biomass of fish assemblages along the Jingjiang section of the Yangtze River over the last decade. Biodiversity Science, 21, 688-698. (in Chinese with English abstract) [孙莎莎, 唐文乔, 郭弘艺, 李辉华, 刘东, 周天 舒, 陈浩洲, 沈林宏, 顾树信 (2013) 靖江沿岸秋季鱼类 群聚的组成特点及其丰度生物量变化. 生物多样性, 21 , 688-698.]

Tang WQ, Zhu TJ, Chen JK, Han HF, Sun Y (2003) Resources and conservation of fishes of Jiuduansha wetland in Changjiang River estuary. Journal of Shanghai Fisheries University, 12(3), 193-200. (in Chinese with English abstract) [唐文乔, 诸廷俊, 陈家宽, 韩洪发, 孙瑛 (2003) 长江口九段沙湿地的鱼类资源及其保护价值. 上海水产 大学学报, 12(3), 193-200.]

Wang Z, Song C, Yan WL, Zhu LF (2019) Biodiversity and spatial pattern of fish in the Pingchuan segment of the upper reaches of Hanjiang River. Resources and Environment in the Yangtze Basin, 28, 1675-1681. (in Chinese with English abstract) [王卓, 宋策, 问文龙, 朱来福 (2019) 汉江上游
平川段鱼类群落多样性及空间格局分析. 长江流域资源 与环境, 28, 1675-1681.]

Wang ZH, Wang K, Zhao J, Zhang SY (2011) Fish community structure and its seasonal change in subtidal sandy beach habitat off southern Gouqi Island. Chinese Journal of Applied Ecology, 22, 1332-1342. (in Chinese with English abstract) [汪振华, 王凯, 赵静, 章守宇 (2011) 枸杞岛潮 下带沙地生境鱼类群落结构和季节变化. 应用生态学报, 22, 1332-1342.]

Warwick RM (1986) A new method for detecting pollution effects on marine macrobenthic community. Marine Biology, 92, 557-562.

Xia JH, Lu JF, Zhou BC, Tan HZ (2009) A preliminary study on fish communities in Suzhou Creek, Shanghai. Journal of Lake Sciences, 21, 538-546. (in Chinese with English abstract) [夏建宏, 陆剑锋, 周保春, 谈慧珍 (2009) 上海 苏州河鱼类群落的初步研究. 湖泊科学, 21, 538-546.]

Yan Y, He S, Chu L (2010) Spatial and temporal variation of fish assemblages in a subtropical small stream of the Huangshan Mountain. Current Zoology, 6, 30-37.

Zhang GQ, Zhang MX, Han ZH, Hu XX (2009) The research on the Suzhou River water quality for the latest 20 years. Environmental Monitoring in China, 25(2), 39-44. (in Chinese with English abstract) [张广强, 张明旭, 韩中豪, 胡雄星 (2009) 苏州河近20年水质状况研究. 中国环境 监测, 25(2), 39-44.]

Zhang SW, Kong XF, Jiang YQ, Lü J, Wu N, Zhang J, Ma R, Zou Y (2015) Review of application and research of biological monitoring technologies in aquatic environment. Environmental Protection Science, 191, 107-111. (in Chinese with English abstract) [张述伟, 孔祥峰, 姜源庆, 吕婧, 吴宁, 张婧, 马然, 邹妍 (2015) 生物监测技术在 水环境中的应用及研究. 环境保护科学, 191, 107-111.]

Zhao MH, Gong YW (2018) Review and achievement of Suzhou Creek environment treatment in 20 years. China Flood and Drought Management, 28(12), 38-41. (in Chinese) [赵敏华, 龚屹嵬 (2018) 上海苏州河治理20年 回顾及成效. 中国防汛抗旱, 28(12), 38-41.]

Zheng YT, Han P, Ni JR, Xiong MH (2019) Studies on structure of fish community and species diversity in Wuhan section of the Yangtze River. Journal of Basic Science and Engineering, 27(1), 29-40. (in Chinese with English abstract) [郑亦婷, 韩鹏, 倪晋仁, 熊美华 (2019) 长江武 汉江段鱼类群落结构及其多样性研究. 应用基础与工程 科学学报, 27(1), 29-40.]

(责任编委: 陈小勇 责任编辑: 间文杰)

\section{附录 Supplementary Material}

\section{附录1 上海苏州河鱼类采集名录}

Appendix 1 Fish list of the Suzhou River in Shanghai

http://www.biodiversity-science.net/fileup/PDF/2020067-1.pdf 
余宏昌, 毕宝帅, 唐文乔, 张亚, 郭弘艺 (2021) 上海苏州河治理中鱼类多样性及群落结构变化. 生物多样性, 2021, 29 (1): 32-42. http://www.biodiversity-science.net/CN/10.17520/biods.2020067

附录1 上海苏州河鱼类采集名录

Appendix 1 Fish list of the Suzhou River in Shanghai

\begin{tabular}{|c|c|c|c|}
\hline 种类 Species & 2001 & 2006 & 2019 \\
\hline \multicolumn{4}{|l|}{ 海鲢目 Elopiformes } \\
\hline \multicolumn{4}{|l|}{ 大海鲢科 Megalopidae } \\
\hline 1 大海鲢 Megalops cyprinoids & $\sqrt{ }$ & & \\
\hline \multicolumn{4}{|l|}{ 鲱形目 Clupeiformes } \\
\hline \multicolumn{4}{|l|}{ 鳀科 Engraulidae } \\
\hline 2 刀鲚 Coilia nasus & $\sqrt{ }$ & $\sqrt{ }$ & $\sqrt{ }$ \\
\hline \multicolumn{4}{|l|}{ 鳗鲡目 Anguilliformes } \\
\hline \multicolumn{4}{|l|}{ 鳗鲡科 Anguillidae } \\
\hline 3 鳗鲡 Anguilla japonica & & & $\sqrt{ }$ \\
\hline \multicolumn{4}{|l|}{ 鲤形目 Cypriniformes } \\
\hline \multicolumn{4}{|l|}{ 鲤科 Cyprinidae } \\
\hline 4 草鱼 Ctenopharyngodon idella & $\sqrt{ }$ & $\sqrt{ }$ & \\
\hline 5 青鱼 Mylopharyngodon piceus & $\sqrt{ }$ & $\sqrt{ }$ & \\
\hline 6 赤眼鳟 Squaliobarbus curriculus & $\sqrt{ }$ & & \\
\hline 7 翅嘴鲌 Culter alburnus & & $\sqrt{ }$ & $\sqrt{ }$ \\
\hline 8 达氏鲌 Culter dabryi & $\sqrt{ }$ & $\sqrt{ }$ & $\sqrt{ }$ \\
\hline 9 蒙古鲌 Culter mongolicus & & & $\sqrt{ }$ \\
\hline 10 尖头鲌 Culter oxycephalus & & & $\sqrt{ }$ \\
\hline 11 红鯺原鲌 Cultrichthys erythropterus & $\sqrt{ }$ & & $\sqrt{ }$ \\
\hline 12 贝氏粲 Hemiculter bleekeri & $\sqrt{ }$ & & $\sqrt{ }$ \\
\hline 13 粲 Hemiculter leucisculus & $\sqrt{ }$ & & $\sqrt{ }$ \\
\hline 14 团头鲂 Megalobrama amblycephala & $\sqrt{ }$ & & \\
\hline 15 鲂 Megalobrama skolkovii & $\sqrt{ }$ & & $\sqrt{ }$ \\
\hline 16 三角鲂 Megalobrama terminalis & $\sqrt{ }$ & & \\
\hline 17 鳊 Parabramis pekinensis & $\sqrt{ }$ & $\sqrt{ }$ & $\sqrt{ }$ \\
\hline 18 寡鳞飘鱼 Pseudolaubuca engraulis & $\sqrt{ }$ & $\sqrt{ }$ & \\
\hline 19 银飘鱼 Pseudolaubuca sinensis & & $\sqrt{ }$ & \\
\hline 20 似鱎 Toxabramis swinhonis & $\sqrt{ }$ & & \\
\hline 21 湖北圆吻鲇 Distoechodon hupeinensis & & & $\sqrt{ }$ \\
\hline 22 似鳊 Pseudobrama simoni & $\sqrt{ }$ & $\sqrt{ }$ & $\sqrt{ }$ \\
\hline 23 鲢 Hypophthalmichthys molitrix & $\sqrt{ }$ & $\sqrt{ }$ & $\sqrt{ }$ \\
\hline 24 鳙鱼 Hypophthalmichthys nobilis & $\sqrt{ }$ & & \\
\hline 25 棒花鱼 Abbottina rivularis & $\sqrt{ }$ & $\sqrt{ }$ & $\sqrt{ }$ \\
\hline 26 花䱻 Hemibrbus maculatus & & & $\sqrt{ }$ \\
\hline 27 麦穗鱼 Pseudorasbora parva & $\sqrt{ }$ & $\sqrt{ }$ & $\sqrt{ }$ \\
\hline 28 黑鰙鳈 Sarcocheilichthys nigripinnis & $\sqrt{ }$ & $\sqrt{ }$ & $\sqrt{ }$ \\
\hline 29 银鮈 Squalidus argentatus & & & $\sqrt{ }$ \\
\hline 30 斑条鮦 Acheilognathus taenianalis & $\sqrt{ }$ & $\sqrt{ }$ & \\
\hline 31 短须䁤 Acheilognathus barbatulus & $\sqrt{ }$ & & \\
\hline
\end{tabular}


余宏昌, 毕宝帅, 唐文乔, 张亚, 郭弘艺 (2021) 上海苏州河治理中鱼类多样性及群落结构变化. 生物多样性, 2021, 29 (1): 32-42. http://www.biodiversity-science.net/CN/10.17520/biods.2020067

\begin{tabular}{|c|c|c|c|}
\hline 种类 Species & 2001 & 2006 & 2019 \\
\hline 32 兴凯鱊 Acheilognathus chankaensis & $\sqrt{ }$ & $\sqrt{ }$ & $\sqrt{ }$ \\
\hline 33 大鳛䁤 Acheilognathus macropterus & $\sqrt{ }$ & & $\sqrt{ }$ \\
\hline 34 越南鮦 Acheilognathus tonkinensis & $\sqrt{ }$ & & \\
\hline 35 高体鳑鲏 Rhodeus ocellatus & $\sqrt{ }$ & $\sqrt{ }$ & $\sqrt{ }$ \\
\hline 36 彩石鳑鲏 Rhodeus lighti & $\sqrt{ }$ & & \\
\hline 37 鲫 Carassius auratus & $\sqrt{ }$ & $\sqrt{ }$ & $\sqrt{ }$ \\
\hline 38 鲤 Cyprinus carpio & $\sqrt{ }$ & $\sqrt{ }$ & $\sqrt{ }$ \\
\hline \multicolumn{4}{|l|}{ 鳅科 Cobitidae } \\
\hline 39 中华花鳅 Cobitis sinensis & & $\sqrt{ }$ & \\
\hline 40 泥鳅 Misgurnus anguillicaudatus & $\sqrt{ }$ & $\sqrt{ }$ & $\sqrt{ }$ \\
\hline 41 大鳞副泥鳅 Paramisgunus dabryanus & $\sqrt{ }$ & & $\sqrt{ }$ \\
\hline \multicolumn{4}{|l|}{ 鲇形目 Siluriformes } \\
\hline \multicolumn{4}{|l|}{ 魭科 Bagridae } \\
\hline 42 长须黄滪鱼 Pelteobagrus eupogon & & $\sqrt{ }$ & $\sqrt{ }$ \\
\hline 43 黄颞鱼 Pelteobagrus fulvidraco & $\sqrt{ }$ & $\sqrt{ }$ & $\sqrt{ }$ \\
\hline 44 光泽黄颡鱼 Pelteobagrus nitidus & & & $\sqrt{ }$ \\
\hline \multicolumn{4}{|l|}{ 鲇科 Siluridae } \\
\hline 45 鲇 Silurus asotus & $\sqrt{ }$ & & $\sqrt{ }$ \\
\hline \multicolumn{4}{|l|}{ 鳉形目 Cyprinodontiformes } \\
\hline \multicolumn{4}{|l|}{ 胎鲟科 Poeciliidae } \\
\hline 46 食蚊鱼 Gambusia affinis & $\sqrt{ }$ & $\sqrt{ }$ & \\
\hline \multicolumn{4}{|l|}{ 领针鱼目 Beloniformes } \\
\hline \multicolumn{4}{|l|}{ 鱵科 Hemiramphidae } \\
\hline 47 间下鱵 Hyporhamphus intermedius & & & $\sqrt{ }$ \\
\hline \multicolumn{4}{|l|}{ 鲻形目 Mugiliformes } \\
\hline \multicolumn{4}{|l|}{ 鲻科 Mugilidae } \\
\hline 48 鲻 Mugil cephalus & $\sqrt{ }$ & & $\sqrt{ }$ \\
\hline 49 鮻 Liza haematocheilus & & & $\sqrt{ }$ \\
\hline \multicolumn{4}{|l|}{ 合鳃鱼目 Synbranchiformes } \\
\hline \multicolumn{4}{|l|}{ 合鳃鱼科 Synbranchidae } \\
\hline 50 黄鳝 Monopterus albus & $\sqrt{ }$ & $\sqrt{ }$ & $\sqrt{ }$ \\
\hline 51 中华刺鳅 Sinobdella sinensis & & & $\sqrt{ }$ \\
\hline \multicolumn{4}{|l|}{ 鲈形目 Perciformes } \\
\hline \multicolumn{4}{|l|}{ 鳜科 Sinipercidae } \\
\hline 52 鳜 Siniperca chuatsi & & & $\sqrt{ }$ \\
\hline \multicolumn{4}{|l|}{ 亚洲海鲇科 Lateolabracidae } \\
\hline \multicolumn{4}{|l|}{53 花鲈 Lateolabrax japonicus } \\
\hline \multicolumn{4}{|l|}{ 沙塘鳢科 Odontobutidae } \\
\hline 54 小黄䵢鱼 Micropercops swinhonis & $\sqrt{ }$ & $\sqrt{ }$ & $\sqrt{ }$ \\
\hline 55 河川沙塘鳢 Odontobutis potamophila & $\sqrt{ }$ & & $\sqrt{ }$ \\
\hline 虾虎鱼科 Gobiidae & & & \\
\hline
\end{tabular}


余宏昌, 毕宝帅, 唐文乔, 张亚, 郭弘艺 (2021) 上海苏州河治理中鱼类多样性及群落结构变化. 生物多样性, 2021, 29 (1): 32-42. http://www.biodiversity-science.net/CN/10.17520/biods.2020067

\begin{tabular}{ccc}
\hline 种类 Species & 2001 & 2006 \\
\hline 56 波氏吻虾虎鱼 Rhinogobius cliffordpopei & & 2019 \\
57 子陵吻虾虎鱼 Rhinogobius giurinus & $\sqrt{ }$ \\
58 纹缟虾虎鱼 Tridentiger trigonocephalus & & $\sqrt{ }$ \\
59 拉氏狼牙虾虎鱼 Odontamblyopus lacepedii & & $\sqrt{ }$ \\
斗鱼科 Belontiidae & $\sqrt{ }$ \\
60 圆尾斗鱼 Macropodus chinensis & & $\sqrt{ }$ \\
鳢科 Channidae & $\sqrt{ }$ \\
61 乌鳢 Channa argus & $\sqrt{ }$ \\
鲀形目 Tetraodontiformes & & $\sqrt{ }$ \\
鲀科 Tetraodontidae & $\sqrt{ }$ \\
62 暗纹东方鲀 Takifugu obscurus & & \\
\hline
\end{tabular}

2001年数据引自夏建宏等(2009); 2006年数据引自陈小华等(2008)。Data for 2011 from Xia et al, 2009; Data for 2006 from Chen et al, 2008.

Chen XH, Li XP, Cheng X (2008) Spatial-temporal distribution of fish assemblages in the upstreams of Huangpu River and Suzhou Creek. Biodiversity Science, 16, 191-196. (in Chinese with English abstract) [陈小华, 李小平, 程曦 (2008) 黄浦江和苏州河 上游鱼类多样性组成的时空特征. 生物多样性, 16, 191-196.]

Xia JH, Lu JF, Zhou BC, Tan HZ (2009) A preliminary study on fish communities in Suzhou Creek, Shanghai. Journal of Lake Sciences, 21, 538-546. (in Chinese with English abstract) [夏建宏，陆剑锋，周保春，谈慧珍 (2009) 上海苏州河鱼类群落 的初步研究. 湖泊科学, 21, 538-546.] 